\title{
Towards a Diagnostic Approach to Climate Adaptation for Fisheries
}

\section{Peat LEITH}

University of Tasmania

Emily OGUER

University of Tasmania

Gretta PECL

University of Tasmania

Eriko HOSHINO

University of Tasmania

Julie DAVIDSON

University of Tasmania

Marcus HAWARD

University of Tasmania

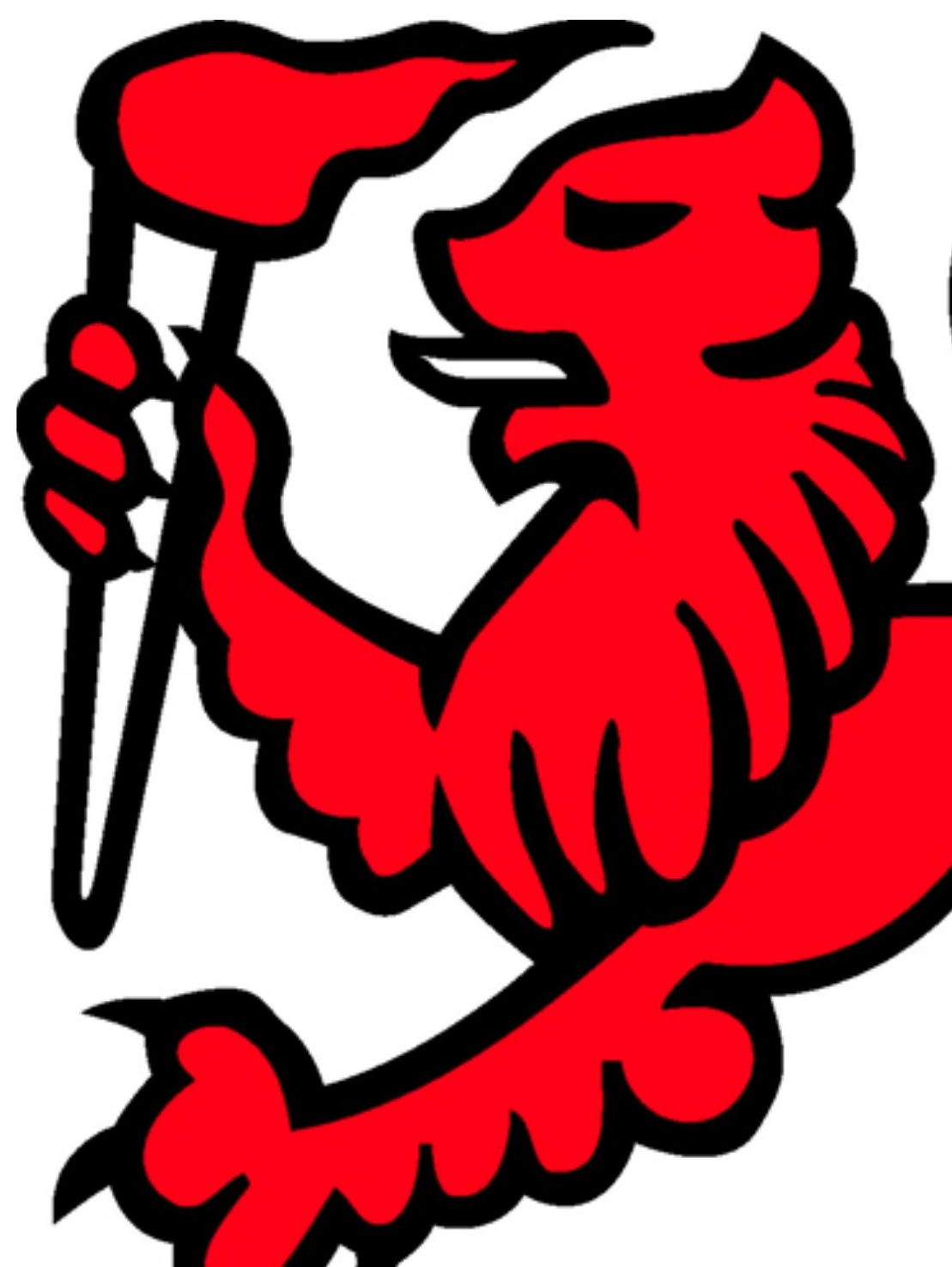




\title{
Towards a diagnostic approach to climate adaptation for fisheries
}

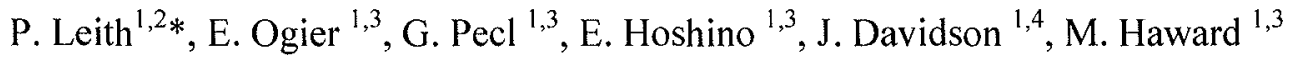

'Adaptation Research Network for Marine Biodiversity and Resources, Private Bag 129, University of Tasmania, Hobart, Tasmania, Australia 7001

${ }^{2}$ Tasmanian Institute of Agriculture, Private Bag 98, University of Tasmania, Hobart, Tasmania, Australia 7001

${ }^{3}$ Institute for Marine and Antarctic Studies, Private Bag 49, University of Tasmania, Hobart, Tasmania, Australia 7001

${ }^{4}$ School of Geography \& Environmental Studies, Private Bag 78, University of Tasmania, Hobart, Tasmania, Australia 7001

* Corresponding author, email: Peat.Leith(autas.edu.au ; phone: +61362262650

Article Note: The research on which this paper is based was conducted within the Adaptation Network for Marine Biodiversity and Resources, funded by the Australian Commonwealth Government.

Abstract

A diagnostic approach to climate change adaptation for fisheries is proposed to define potential climate adaptation pathways in well-managed fisheries. Traditional climate vulnerability and risk assessments tend to focus on biophysical threats and opportunities and thereby what needs to be done to adapt to climate change. Our diagnostic approach moves from such analysis to focus on how the processes of adaptation and development of adaptive capacity can be structured to achieve desired outcomes. Using a well-grounded framework, the diagnostic approach moves from system description to characterization of challenges and opportunities, through two stages of analysis and validation, to the definition and embedding of adaptation options and pathways. The framework can include all contextually relevant variables and accommodate evaluation of adaptation outcomes and comparisons across scales and contexts. Such an approach can serve as a basis for enabling stakeholders to identify challenges and opportunities, and to explore and prioritize options for development and implementation of legitimate adaptation pathways.

Keywords: collaborative management, adaptation, climate change, fisheries, diagnostic approach, governance

Word Count: 6027 excluding tables and figures 


\section{Towards a diagnostic approach to climate adaptation for fisheries}

\section{Introduction}

The gulf between knowledge and action is well recognized across many domains where science is funded to inform decision-making that affects public and private interests (Jasanoff and Wynne 1998; Leith et al. 2012; McNie 2007; Pohl 2008; Reyers et al. 2010). It is particularly problematic in fields where substantial uncertainties and inter-dependencies exist among biophysical, social, economic and political system drivers (Poteete et al. 2010). Developing strategies to adapt fisheries management to climate change is an example where long-term uncertainties associated with projected climate change impacts are just one of the many issues that limit uptake of climate adaptation.

While some examples of climate change adaptation within a particular fishery exist (Frusher et al. 2013), planned adaptation is still in its infancy. Resourceconstrained public sector managers often already consider their processes to be adaptive (Frusher et al. 2013; Grafton 2010). Much adaptation as a result remains understandably incremental, progressing in response to seasonal and inter-annual variability (Frusher et al. 2013). This may not be adequate if climate change results in fundamental changes, such as a significant or abrupt shift in stock recruitment, or the carrying capacity of a stock (Brander 2010). There is rarely substantial social, economic or political incentives for planned adaptation to long'term climate change, except where obvious changes have occurred, such as major shifts in stock abundance or distribution of important commercial species (e.g. Astthorsson et al.2012). Challenges or barriers to planned adaptation are commonplace and represent a series of mostly sound reasons why knowledge about climate impacts and vulnerabilities does not usually translate into welldirected action to ameliorate them (Moser and Ekstrom 2010).

In this paper, we draw on lessons from climate change adaptation research in Australian fisheries to argue that adaptation in well-managed fisheries can build 
on existing processes through the application of sound process coupled with a robust diagnostic framework. Although our experience is in Australian fisheries, we suspect that the approach described would be applicable to commercial fisheries in many developed country contexts, particularly where co-management is ascendant, and the fishery is at a scale to support such planning. Through work with larger fisheries it may be possible to refine the process to make it scalable for smaller and artisanal fisheries. We propose a structured approach to identifying barriers and opportunities to planned adaptation, expressly to prioritize options, and explore legitimate adaptation pathways. We focus on planned adaptation, defined as an ongoing, intentional process to contend with particular biophysical or socio-economic conditions, risks and/or uncertainties (Füssel 2007).

This framework- and process-based approach builds on contemporary management tools coupled with the understanding that many constraints on adaptation in fisheries are not scientific, but institutional and social (Brander 2010). Contemporary approaches, such as Management Strategy Evaluation (MSE) recognize the importance of formally accounting for risks and uncertainties in fisheries management. MSE also defines robust management strategies under a range of scenarios about alternative states of nature (e.g. de la Mare 1996; Punt and Smith 1999; Holland 2010) and can provide for detailed dialogue between industry, scientists and managers, thus allowing for ongoing adjustments in harvest rules (Bunnefeld et. al. 2011; Smith et al. 1999). MSE thus provides potential for incremental adaptation. However, MSE tends to focus on biological and biophysical variables (Plaganyi et al. 2012). In intentional adaptation, social and economic variables are often the key constraints to adaptation (Moser and Ekstrom 2010). These are often also phenomena that are most amenable to intervention. Additionally, MSE is usually based on singlespecies management and may limit long-term management of stocks under climate change, unless spatial structure, environmental forcing, and a broad ecosystem perspective are considered (Plaganyi et al. 2011). Moreover, MSE does not necessarily provide stakeholders with a clear or legitimate pathway to climate adaptation, at least on its own. 
We propose a practical participatory approach through which adaptation options or pathways can be collaboratively defined, tested and explored. Such participatory assessment can include multiple and cross-scale drivers of change: from international treaties and obligations, geo-politics and global markets, at the broadest scale, to familial and cultural institutions, and identities and relations at a local scale. This approach recognizes that, for adaptation, many policy, social, economic, human, political, cultural as well as environmental variables are at play (Eakin and Lemos 2006).

Fisheries governance around the world is moving away from top-down management (where scientists and public sector managers define regulatory controls) towards more collaborative approaches in which fishers and other stakeholders are involved in decision-making processes (Wilson et al., 2003). The diagnostic approach described in this paper is in line with this trend towards collaborative management and extends a partnership model between governments and fisheries sectors (FRDC, 2008, Smith et al., 1999) to include interdisciplinary researchers as stakeholders.

In the following section we make the case for a diagnostic approach to fisheries adaptation. We then describe how Ostrom's (2009) diagnostic framework can be adapted to fisheries adaptation, and finally, we outline a collaborative process through which the diagnostic process could be applied to embed adaptation as an integral component of effective fisheries management.

\section{Barriers and drivers of adaptation in fisheries}

Marine-focused adaptation studies have made an important contribution to understanding the vulnerability, sensitivity and risks faced by Australian marine systems to climate change (Johnson et al. 2011; Hobday et al. 2008; Pecl et al. 2009). The development and evaluation of workable adaption pathways for associated fisheries has been far more limited. Following Moser and Ekstrom (2010), our experience in fisheries adaptation research (Davidson et al. 2013; Frusher et al. 2013; Haward et al. 2013; Leith and Haward 2010; Madin et al. 2012; Nursey-Bray et al. 2012; Pecl et al. 2009) has highlighted structural, 
institutional, social and human challenges for adaptation within particular fisheries. These are briefly described below as a series of barriers under six generic headings, as follows:

\subsection{Focus on reduction of uncertainty over decision-making under uncertainty}

While climate change research provides a broad consensus about the direction of change for local and regional marine systems, we have little predictive capability regarding the degree of change, the timeframes of impacts, and whether impacts will be gradual or abrupt (Miller et al. 2010). Australian scientific and policy responses have generally prioritized reduction of such uncertainties rather than developing capacity for decision-making in the context of largely irreducible uncertainty (Nelson et al. 2008). Global climate models and their application in other biophysical and economic models (e.g. models which predict changes in abundance or recruitment of a target species) cannot 'predict' per se (Oreskes 1994). Through sensitivity analysis, such modeling can substantially improve understanding of system characteristics, and how they may respond to variability and shocks. However, they are rarely able to provide robust risk assessments that decision-makers can apply. There is a growing literature on processes and strategies for adaptive management and the development of approaches that are robust across diverse scenarios (Dessai et al. 2009). In such approaches, science provides scenarios to support processes and institutions that enable proactive and adaptive management (Nelson et al. 2008).

\subsection{Lack of clear goals for adaptation research}

Developing and evaluating adaptation pathways is complicated by the lack of well articulated or prioritized management objectives. Instruments such as management plans include some objectives for individual fisheries yet rarely specify the relative importance of these. Plans also commonly include objectives that may be countervailing such as achieving maximum economic benefit for industry and maximizing local employment opportunities. Generally, few effective mechanisms are applied to deal with divergent societal values that underpin such objectives, or to clarify how synergies and trade-offs between 
competing objectives are dealt with when evaluating alternative adaptation strategies (Pascoe et al. 2009).

A common challenge encountered in the adaptation planning phase includes gaining the agreement of diverse stakeholders on the goals of adaptation (Moser and Ekstrom 2010). Definitions of adaptation continue to be contested (Adger et al. 2005) and, as a result, there is often little agreement as to what criteria should be applied to determine whether adaption actions have been (or would be) successful and sustainable (Doria et al. 2009). Assessing adaptation options against clearly defined goals for a system requires a transparent, systematic and broadly repeatable approach. Doria et al. (2009) note that adaption actions should be evaluated by those adapting or affected by adaptation.

\subsection{Divergent expectations of adaptation research}

Across resource management contexts, managers, funders and researchers often have divergent expectations and perceptions of the possible role of researchers to influence management and achieve adaptation outcomes. Within fisheries management agencies, perspectives of adaptation research vary. Traditional fisheries management tends to maintain a purchaser-provider model as guiding the relationship between government and researchers. Reminiscent of Winston Churchill's notion that "scientists should be on tap not on top" (quoted in Churchill 1965) this approach can make application of science discretionary by maintaining decisions within a political sphere. In the purchaser-provider model, adaptation projects tend to occur as isolated research exercises that are not integrated with or embedded in broader fisheries research, monitoring, assessment and management processes (Miller et al. 2010). Contrastingly, research funding agencies often support adaptation research on the expectation that it will directly lead to changes in management.

\subsection{Barriers to participation and collaboration}

Climate variability and change are often seen as minor concerns among stakeholders with many competing demands on their time. Such issues tend to be of lower concern when compared to immediate economic viability and resource security or access (Nursey-Bray et al. 2012). Distrust between different 
stakeholders involved in a fishery can inhibit collaboration (Glenn et al., 2012). For instance, in many countries, there has historically been little incentive for scientists and fishers to work together and develop a shared sense of purpose and language. Relationship building, collaboration and stakeholder participation are sometimes difficult to resource on an ongoing basis in both research or management, making inter- and trans-disciplinary assessment of risks and opportunities for adaptation challenging (Degnbol et al. 2006; Jacobsen et al. 2012; Miller et al. 2010).

\subsection{Inadequate levels of support for monitoring of system states}

Ongoing and appropriate data streams are necessary to ensure management can be flexible and adaptive, and success and failure can be properly evaluated. Trends in biological and socio-economic indicators need to be available, appropriate and integrated into decision-processes. Adaptive management is reliant on timely and relevant information (Moser and Ekstrom 2010), and so inadequate monitoring can and does stall adaptation. Too often monitoring and evaluation activities that could support adaptive management are focused on compliance rather than learning (e.g., Lockwood et al. 2009).

\subsection{Resourcing and capacity constraints}

A key barrier to adaptation action is resourcing within fisheries management agencies. In our experience, managers and researchers have often found it difficult to clearly articulate the specific risks and opportunities that need to be managed, resulting in adaptation being seen as a generic, amorphous or insubstantial concern, which in turn limits stakeholder or political interest. Making the case for 'soft' interventions through, for example, policy innovation and building improved social capital and adaptive capacity is usually a substantial challenge in such resource-constrained environments.

The barriers outlined above present substantial constraints to the practice of adaptation in Australian fisheries. Although these barriers are sometimes directly investigated in adaptation research, they are rarely systematically addressed within existing governance arrangements of a fishery. In the following sections, 
we propose an approach which could embed adaption within effective marine governance systems through systematic diagnosis of barriers and opportunities.

\section{Towards a diagnostic approach to climate adaptation}

In this section, we draw on existing literature to detail why a diagnostic approach can be useful to overcome barriers to adaptation. Diagnosis is a useful metaphor to describe a process-driven and deliberative approach to identifying how the properties and dynamics of a system result in particular functions, structures and outcomes, and whether these are desirable or otherwise. A core challenge for diagnosis is integrating human values and science in the decision-making processes. For example, the resolution of 'desirability' of social-ecological system states is rightfully more democratic than scientific (Holling et al. 1998; Nelson 2011). Yet the processes which inform technical research, monitoring and evaluation of biophysical systems, policy instruments, models and management regimes tend to be more technocratic than explicitly driven by debates or deliberation over values.

In a complex system, such as a fishery, identification of cause and effect in precise terms is rare. Nevertheless, it is often possible to identify and, more importantly, agree on aspects of the broad system that constrain and enable strategic and/or tactical decision-making. These can range from biophysical to economic and social factors. For instance, lack of scientific certainty about the mechanisms that lead to seasonal variability in recruitment to industry may be perceived as a fundamental constraint. Such uncertainties may be less intractable than addressing factions within an industry that limit decision-making within the industry. Threats and solutions to the problems that beset fisheries can also stem from outside the domain of the fishery, and diagnostic approaches may facilitate intra-sectoral management in the developing world (Andrew et al. 2007). 
Moser and Ekstrom (2010) argue that barriers to adaptation can be addressed through normal problem management processes: identification and prioritization of options, monitoring and evaluation of successes and failures. Identifying barriers and drivers of change is a diagnostic task by which impediments to adaptation can be revealed, agreed upon and, where appropriate, acted upon. It should be noted that legitimate decisions may be to do nothing or 'wait and see', where such inaction is deliberate.

Diagnosis requires trans-disciplinary collaboration in order to ensure processes and decisions are legitimate (Cash et al. 2003); diverse, relevant knowledge is included (Pohl 2008); and workable policy options that balance multiple objectives at different scales can be evaluated (Nelson et al. 2008). These outcomes may require cultural change, new ways of thinking, and the ability to humbly, critically and openly reflect on failures as well as successes; practices that are currently not espoused in most public organizations (Jasanoff 2003). These personal and organizational traits are increasingly recognized as core elements of institutional adaptive capacity (Armitage 2005).

The medical analogy of diagnosis is useful in describing this process, but only to a point. Health in complex systems, such as fisheries, is more ambiguous and values-dependent than in humans (cf. Halpern et al. 2012). An essential task of any approach that seeks diagnosis in social-ecological systems is facilitating the articulation of goals agreed on by stakeholders. The recruitment and selection of appropriate stakeholders engaged in decision making is in itself vexed.

Nevertheless, useful principles exist by which key questions (e.g. 'what is at stake and for whom?') can guide approaches (Innes and Booher 2003) and processes (Bryson 2004) for selecting and engaging participants.

The development of adaptation pathways can clarify strategic goals and review management and governance in relation to emerging knowledge of system drivers, and changes in these. This process is more akin to a review of fisheries governance than a side project about climate change. Defining adaptation pathways is thus not something to be undertaken lightly - it may precipitate desire for reorganization of fisheries management. However, our proposed diagnostic 
approach is unlikely to rapidly impose new systems. Because it is oriented by deliberation, it is more likely to increase capacity for adaptive governance, build adaptive capacity and systematize a watching brief on potential risk factors and opportunities associated with system drivers (Nelson et al. 2008). .

\section{A framework for diagnosis}

The framework detailed below draws on Ostrom's $(2009 ; 2007)$ scheme for analyzing social-ecological systems (SES), although we have unpacked some elements and make more explicit reference to fisheries systems. A central concern for diagnosis is disaggregation. Complex systems need to be made tractable to stakeholders, and a useful means of doing this is by identifying and agreeing on key elements that are vital to system function broadly and adaptation specifically. For fisheries systems, this process will require different forms of expertise to be applied to identifying and analyzing system characteristics and dynamics in relation to adaptation and strategic long-term planning (Ostrom and Cox 2010). Ultimately, key interactive elements will need to be considered together, but initially it is useful to identify the variables, processes and interactions that can be agreed upon as defining a system's structure and function. Such a process can also reveal points of tension and difference within and across a marine governance context, which themselves can be critical to defining adaptation options and possibilities.

Frameworks are a useful method of achieving these purposes because, as Ostrom (2011) observes, they help to establish the key variables and the relationships between them, and how these variables hold with or challenge existing theory. To adopt a framework that can assist in developing adaptation pathways we suggest that four essential criteria need to be met. The framework must: be clear and tractable to stakeholders; be open enough to include all relevant variables from social, economic and ecological components of a fishery; be consistent enough to enable comparison and meta-analysis across cases and systems; and be useful for defining goals and reflecting outcomes through monitoring and evaluation. Ostrom's $(2009,2007)$ ontological framework meets these requirements. Moreover, its foundations in management of common pool 
resources (CPR) befit fisheries management, and especially collaborative management. As a nested framework, it does not predefine variables that are important in any particular fishery, yet still allows for comparison across contexts by providing a tiered approach to disaggregation. At the first level, only four subsystems are used to encompass all lower level system characteristics: resource systems, resource units, governance systems and users. These are contextualized by a fifth category - social, economic and political settings - which may drive decision-making within the system but are considered as external because they are not influenced substantially by action within the system (Urwin and Jordan 2008). For the purpose of working through the barriers and drivers of adaptation as a process, the sub-systems and context can be defined in general terms (Table 1). This approach allows for consistent use of a credible and legitimate framework without a priori imposition of a set of variables which can pre-ordain outcomes.

Table 1: Definitions of first order variables to be used for eliciting higher order variables in fisheries cases (adapted from Ostrom 2009; 2007).

\begin{tabular}{|c|c|}
\hline First Order Variables & Description \\
\hline $\begin{array}{l}\text { Social, Economic and Political Setting } \\
\text { (S) }\end{array}$ & $\begin{array}{c}\text { The external variables which structure action within a } \\
\text { fishery but are not easy to change from within the } \\
\text { system }\end{array}$ \\
\hline Resource system (RS) & $\begin{array}{c}\text { The physical and biological aspects and processes of } \\
\text { the system that constrain or enable adaptation }\end{array}$ \\
\hline Resource units (RU) & $\begin{array}{c}\text { Characteristics of the resource itself (e.g. of the } \\
\text { particular fish species) that affect how adaptable the } \\
\text { fishery is to change }\end{array}$ \\
\hline Governance system (GS) & $\begin{array}{l}\text { The formal and informal organizations, institutions, } \\
\text { relationships, networks and rules that govern action } \\
\text { within the system and thus affect adaptation and } \\
\text { adaptive capacity }\end{array}$ \\
\hline Users (U) & $\begin{array}{l}\text { The traits of the resource users and other stakeholders, } \\
\text { and interactions among them, including their use of } \\
\text { technology, information and knowledge }\end{array}$ \\
\hline
\end{tabular}

At the second tier, many more variables potentially come into play. Decades of detailed empirical analysis of CPR management and collective action have 
identified 52 second tier variables that recurrently underpin system structure and function (Table 1 in supplementary material, adapted from Ostrom 2009). Ten of these variables consistently underpin the ability to self organize to manage CPR problems (see supplementary material, Ostrom 2007) and are likely to be influential in developing adaptation pathways within marine governance and management.

Drawing on our experience in adaptation research in fisheries and the adaptation literature, we suggest that Ostrom's second order variables pertain to adaptive capacity and the definition of adaptation options (Supplementary material). These are not meant to pre-empt or prioritize the actual identification of second or higher order variables, but provide a heuristic for the way the variables are related to adaptation in fisheries systems.

Analytically and diagnostically, second and higher order variables could be used in an action research context to pose questions about efficacy and equity of adaptation options or pathways for a given fishery. Such questioning is derived through imaginatively interrogating the status, trends, variability and interactions across key variables once they are defined. For instance, a highly productive system (RS5) of high value fish (RU4) within a smaller geographical area (RU7) may be associated with better-organized resource users than a similarly productive system that is more distributed. Highly distributed systems with low productivity/value may be more vulnerable to generic or specific change, unless other livelihood options (a higher order variable under U2) are present or possible. Where there are relatively high numbers of users (U1) over broad geographical area (RU7), opportunities for face-to-face meetings are reduced. Consequently, a higher proportion of users will be unknown to each other (U6), may be less able to cooperate (see Ebenhöh and Pahl-Wostl 2010 ) and have less consistent mental models of the fishery system (U7).

These sorts of interactions appear to underlie fundamental aspects of adaptive capacity (Armitage 2005), yet need to be tested in specific contexts in order to identify barriers and opportunities for adaptation and thereby the pathways that best fit within a specific fisheries context. We have argued that Ostrom's 
framework provides a robust and tractable foundation for facilitating such deliberation. In the following section we briefly outline a process that could be employed to embed climate adaptation within a collaborative fisheries governance context while building capacity for ongoing adaptation.

The six stage process (see overview in Figure 1 and described in the supplementary material) is instigated by an inter-disciplinary research team via analyses of secondary socio-economic data, biophysical data and publications. A series of key-informant interviews provides preliminary contextual variables. The framework is used as a lens to analyse and organize variables continually throughout the process. For instance, the first order variables (Table 1) would be applied to organize discussion in collaborative workshops (stages 2, 5 and 6, Figure 1). In stage 5 of the process, adaptation pathways are developed drawing on the earlier diagnostic work to understand and evaluate constraining and enabling elements of the fisheries system. Throughout this, and subsequent processes, attention would be needed to build capacity and trust within the team and to actively and reflexively expand a network across industry bodies, management agencies, relevant NGOs, and among fishers.

It should be noted that the process outlined above is analytically partial. A complete and impartial analysis of a resource system's characteristics that underpin its vulnerability, sustainability, resilience or the capacity to govern the system is not possible (Ostrom 2005). The numerous variables that potentially affect adaptation mean that millions of potential combinations exist, especially if each variable is described through numerous nominal categories. For similar reasons, setting 'optimal' policy and institutional arrangements is neither possible nor the aim of such work. Rather, the ideal of diagnosis is to build more adaptive governance systems, capable of learning driven by biophysical, socio-political and/or cultural processes (Nelson et al. 2008). 


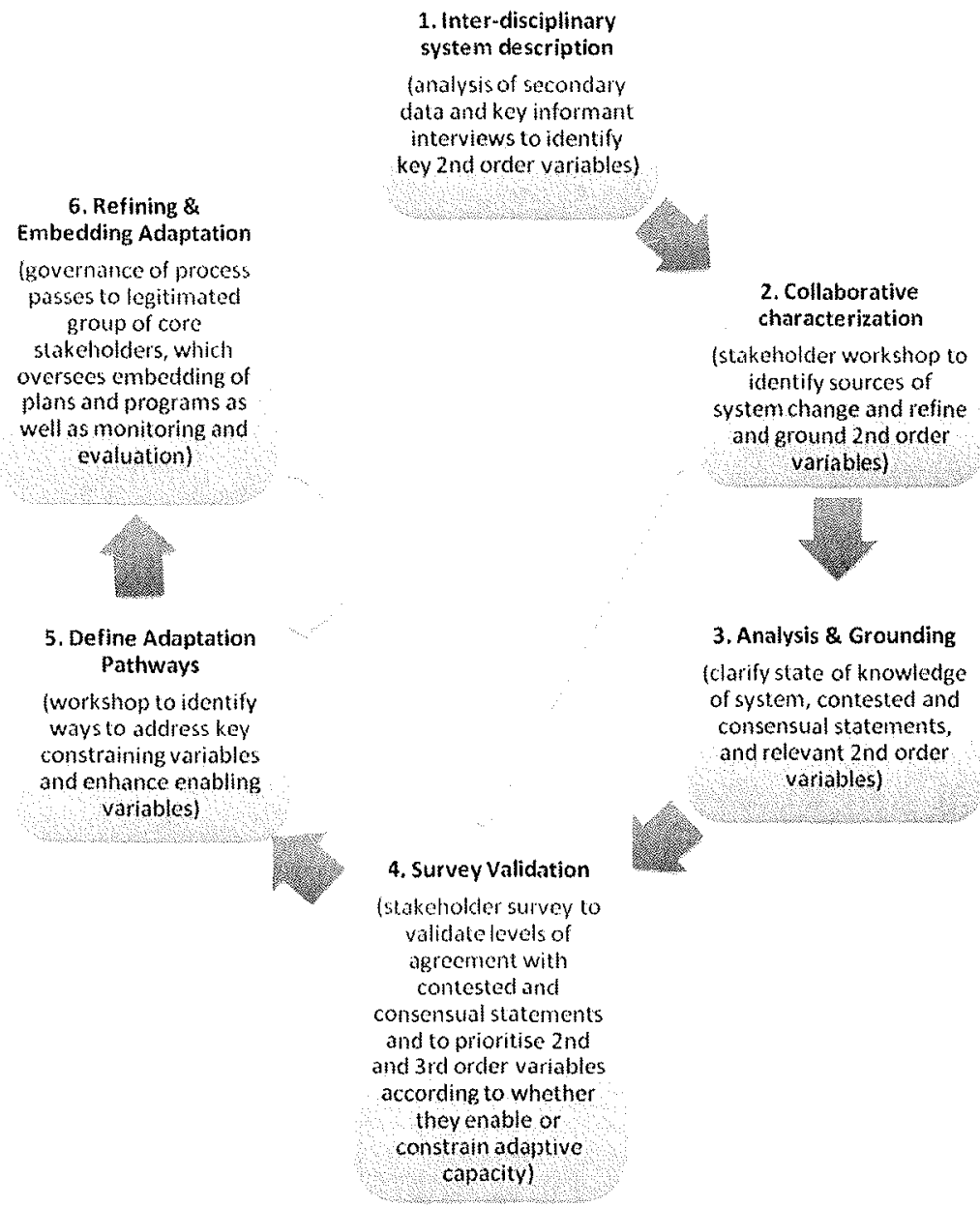

Figure 1. Schematic of the diagnostic process for developing adaptation pathways for a fishery

\section{Concluding comment}

Emerging collaborative arrangements in fisheries governance offer a substantial opportunity to build pathways for climate adaptation using a diagnostic approach. Such work will require strong commitment from and collaboration between fishers, public sector managers, scientists and other stakeholders to develop and embed adaptation within fisheries governance. The trans-disciplinary approach developed in this paper is designed to integrate our best science with knowledge of managers and fishers, and ultimately passes ownership of adaptation to the key players in fisheries governance. At the same time, it aims to build capacity within fisheries governance to deal more effectively and proactively with uncertainty and 
indeterminacy. Through the disaggregation of the system into key second and higher order variables, and the clarification of the barriers and opportunities for adaptation associated with these variables, adaptation options and their implementation can be monitored at a systems level and comparable across contexts. The process suggested enables legitimate approaches to adaptation to be developed, but also effectively evaluated in relation to objectives and measures of success agreed on through the latter stages of the diagnostic process. This diagnostic approach enables collaborative evaluation of policy options, programs and plans for adaptation which can then be credibly and legitimately embedded in the governance of the fishery and potentially compared across fisheries. 
Adger NW, Arnell NW, Tompkins EL (2005) Successful adaptation to climate change across scales. Global Environ Change 15 (2):77-86

Andrew NL et al (2007) Diagnosis and management of small-scale fisheries in developing countries. Fish and Fisheries 8: 227-240.

Armitage D (2005) Adaptive capacity and community-based natural resource management. Environ Manage 35 (6):703-715

Astthorsson OS, Valdimarsson H, Gudmundsdottir A, Oskarsson G (2012) Climate-related variations in the occurrence and distribution of mackerel (Scomber scombrus) in Icelandic waters. ICES J Mar Sci 69 (7): 1289-1297

Brander KM (2007) Global fish production and climate change. Proc Natl Acad Sci USA 104 (50):19709-19714

Brander KM (2010) Impacts of climate change on fisheries. J Mar Syst, 79(3-4), 389-402

Bryson JM (2004) What to do when stakeholders matter: stakeholder identification and analysis techniques. Pub Manag Rev 6 (1):21-53

Bunnefeld N, Hoshino E, Milner-Gulland EJ (2011) Management strategy evaluation: a powerful tool for conservation? Trends Ecol Evol 26: 441-447

Cash DW, Buizer J (2005) Knowledge-action systems for seasonal to interannual climate forecasting. Roundtable on Science and Technology for Sustainability Policy and Global Affairs. National Research Council, Washington D.C.

Cash DW, Clark WC, Alcock F, Dickson NM, Eckley N, Guston DH, Jager J, Mitchell RB (2003) Knowledge systems for sustainable development. Proc Natl Acad Sci USA 100 (14):80868091

Churchill RS (1965) Twenty-one years. Houghton Mifflin, Boston.

Davidson I, van Putten IE, Leith P, Nursey-Bray M, Madin E, Holbrook N.I (2013) Towards Operationalizing Resilience Concepts in Australian Marine Sectors Coping with Climate Change. Ecol Soc 18(3):4

Degnbol P, Gislason H, Hanna S, Jentoft S, Raakjær Nielsen J, Sverdrup-Jensen S, Clyde Wilson D (2006) Painting the floor with a hammer: Technical fixes in fisheries management. Mar Policy $30(5): 534-543$

de la Mare WK (1996) Some recent developments in the management of marine living resources. In: Floyd RB, Shepherd AW, De Barro PJ (eds) Frontiers of Population Ecology, CSIRO Publishing, Melbourne, Australia, pp 599-616

Dessai S, Hulme M, Lempert R, Pielke Jr R (2009) Do We Need Better Predictions to Adapt to a Changing Climate? EOS Trans Am Geophys Union 90 (13):111 doi: 10.1029/2009EO130003

Doria MdF, Boyd E, Tompkins EL, Adger WN (2009) Using expert elicitation to define successful adaptation to climate change. Environ Sci Policy $12(7): 810-819$

Eakin H, Lemos MC (2006) Adaptation and the state: Latin America and the challenge of capacity-building under globalization. Global Environ Change 16 (1):7-18

Ebenhöh E, Pahl-wostl C (2010) The grammar of institutions: The challenge of distinguishing between strategies, norms, and rules. Ration Soc 22:445-475 
FRDC (2008) Co-management: Managing Australia's fisheries through partnership and delegation. Report of the Fisheries Research and Development Corporation's national working group on the fisheries co-management initiative - Project No. 2006/068. Fisheries Research and Development Corporation, Canberra.

Frid CLJ, Paramor OAL (2012) Feeding the world: what role for fisheries? ICES J Mar Sci 69 (2): $145-150$

Frusher S, Hobday A, Jennings SM, Creighton C, D'Silva D, Haward M, Holbrook NJ, NurseyBray M, Pecl GT, van Putten I (2013) The short history of research in a marine climate change hotspot - from anecdote to adaptation in south-east Australia. Rev Fish Biol Ecol (in revision)

Füssel HM (2007) Adaptation planning for climate change: concepts, assessment approaches, and key lessons. Sustain Sci 2 (2):265-275

Glenn H, Tingley D, Sánchez Maroño S, Holm D, Kell L, Padda G, Runar Edvardsson I, Asmundsson J, Conides A, Kapiris K, Bezabih M, Wattage P Kuikka S (2012) Trust in the fisheries scientific community. Mar Policy 36:54-72

Grafton QR (2010) Adaptation to climate change in marine capture fisheries. Mar Policy 34 (3):606-615

Gullet W (2008) Fisheries law in Australia. LexisNexis Butterworths, Chatswood, NSW Halpern BS, Longo C, Hardy D, McLeod KL, Samhouri JF, Katona SK, Kleisner K, Lester SE, O/'Leary I, Ranelletti M, Rosenberg AA, Scarborough C, Selig ER, Best BD, Brumbaugh DR, Chapin FS, Crowder LB, Daly KL, Doney SC, Elfes C, Fogarty MJ, Gaines SD, Jacobsen KI, Karrer LB, Leslie HM, Neeley E, Pauly D, Polasky S, Ris B, St Martin K, Stone GS, Sumaila UR, Zeller D (2012) An index to assess the health and benefits of the global ocean. Nature 488 (7413):615-620

Haward M, Davidson J, Lockwood M, Hockings M, Kriwoken L (2013) Climate Change, Scenarios and Marine Biodiversity Conservation. Mar Policy 38:438-446.

Hobday AJ, Poloczanska ES, Matear RJ (2008) Implications of Climate Change for Australian Fisheries and Aquaculture: a preliminary assessment. Report to the Department of Climate Change. Canberra, Australia.

Holland DS (2010) Management Strategy Evaluation and Management Procedures: Tools for Rebuilding and Sustaining Fisheries. OECD Food, Agriculture and Fisheries Working Papers No. 25, OECD Publishing.

Holling CS, Berkes F, Folke C (1998) Science, Sustainability and Resource Management. In: Berkes F, Folke C (eds) Linking Social and Ecological Systems: management practices and social mechanisms for building resilience. Cambridge University Press, London, pp 342362

Innes JE, Booher DE (2003) Collaborative policy-making: governance through dialogue. In: Hajer M, Wagenaar H (eds) Deliberative Policy Analysis: understanding governance in the network society. Cambridge University Press, Cambridge, UK, pp 33-59

Jacobsen RB, Wilson DCK, Ramirez-Monsalve P (2012) Empowerment and regulation dilemmas in participatory fisheries science. Fish and Fisheries 13:291-302 
Jasanoff S (2003) Technologies of humility: citizen participation in governing science. Minerva 41:223-244

Jasanoff S, Wynne B (1998) Science and decision making. In: Rayner S, Malone EL (eds) Human Choice and Climate Change, vol 1: Societal Framework. Batelle Press, Columbus, Ohio, pp $1-87$

Johnson CR, Banks SC, Barrett NS, Cazassus F, Dunstan PK, Edgar GJ, Frusher SD, Gardner C, Haddon M, Helidoniotis F, Hill KL, Holbrook NJ, Hosie GW, Last PR, Ling SD, Melbourne-Thomas J, Miller K, Pecl GT, Richardson A.J, Ridgway KR, Rintoul SR, Ritz DA, Ross DJ, Sanderson JC, Shepherd SA, Slotwinski A, Swadling KM, Taw N (2011) Climate change cascades: Shifts in oceanography, species' ranges and subtidal marine community dynamics in eastern Tasmania. J Exp Mar Biol Ecol 400 (1-2):17-32

Leith PB, Coffey B, Haward M, O'Toole K, Allen S (2012) Improving science uptake in coastal zone management: principles for science engagement and their application in south-eastern Tasmania In: Stocker L, R. K (eds) Sustainable Coastal Management and Climate Adaptation. CSIRO Publishers, Melbourne, Australia, pp 135-156

Leith PB, Haward M (2010) Climate Change Adaptation in the Australian Edible Oyster Industry: an analysis of policy and practice. University of Tasmania, Hobart, Tasmania.

Linstone, HA, Turoff M Eds. (1975) The Delphi method: techniques and applications. AddisonWesley, Reading.

Lockwood M, Davidson J, Curtis A, Stratford E, Griffith R (2009) Multi-level Environmental Governance: lessons from Australian natural resource management. Aust Geogr 40 (2):169186.

Madin EMP, Ban NC, Doubleday ZA, Holmes TH, Pecl GT, Smith F (2012) Socio-economic and management implications of range-shifting species in marine systems. Global Environ Change $22(1): 137-146$.

McNie EC (2007) Reconciling the supply of scientific information with user demands: an analysis of the problem and review of the literature. Environ Sci Policy 10 (1):17-38

Miller K, Charles A, Barange M, Brander K, Gallucei VF, Gasalla MA, Khan A, Munro G, Murtugudde R, Ommer RE (2010) Climate change, uncertainty, and resilient fisheries: institutional responses through integrative science. Prog Oceanog 87 (1-4):338-346

Moser S, Ekstrom JA (2010) A framework to diagnose barriers to climate change adaptation. Proc Natl Acad Sci USA 107 (51):22026-22031

Nelson DR (2011) Adaptation and resilience: responding to a changing climate. Wiley Interdisciplinary Reviews: Climate Change 2 (1):113-120

Nelson RA, Howden M, Stafford Smith M (2008) Using adaptive governance to rethink the way science supports Australian drought policy. Environ Sci Policy 7:588-601

Nursey-Bray M, Pecl GT, Frusher S, Gardner C, Haward M, Hobday AJ, Jennings S, Punt AE, Revill H, van Putten I (2012) Communicating climate change: climate change risk perceptions and rock lobster fishers, Tasmania. Mar Policy 36 (3):753-759

Oreskes N, Shrader-Frechette K, Belitz K (1994) Verification, validation, and confirmation of numerical models in the earth sciences. Science 263: 641-646 
Ostrom E (2005) Understanding Institutional Diversity. Princeton University Press, New Jersey

Ostrom E (2007) A diagnostic approach for going beyond panaceas. Proc Natl Acad Sci USA 104

(39):15181-15187

Ostrom E (2009) A general framework for analyzing sustainability of social-ecological systems.

Science 325 (5939):419-422

Ostrom E (2011) Background on the institutional analysis and development framework. Policy

Stud J 38 (1): 7-27

Ostrom E and Cox M (2010) Moving beyond panaceas: a multi-tiered diagnostic approach for social-ecological analysis. Environ Conserv 37 (4) 451-463

Pascoe S, Dichmont CM, Brooks K, Pears R, Jebreen E (2013) Management objectives of Queensland fisheries: putting the horse before the cart. Mar Policy 37: 115-122

Pascoe S, Proctor W, Wilcox C, Innes J, Rochester W, Dowling N (2009) Stakeholder objective preferences in Australian Commonwealth managed fisheries. Mar Policy 33 (5):750-758

Pecl GT, Frusher SD, Gardner C, Haward MG, Hobday AJ, Jennings SM, Nursey-Bray MJ, Punt AE, Revill H, Van Putten IE (2009) The east coast Tasmanian rock lobster fishery vulnerability to climate change impacts and adaptation response options. Department of Climate Change, Commonwealth of Australia, Australia

Plagányia EE, van Putten I, Hutton T, Denga RA, Dennisa D, Pascoe S, Skews TD, Campbell RA (2012) Integrating indigenous livelihood and lifestyle objectives in managing a natural resource. Proc Natl Acad Sci USA 110 (9):3639-3644

Plagányia EE, Weeks SL, Skews TD, Gibbs MT, Poloczanska ES, Norman-Lopez A, Blamey LK, Soares M, Robinson WML (2011) Assessing the adequacy of current fisheries management under changing climate: a southern synopsis. ICES J Mar Sci 68(6): 1305-1317

Pohl C (2008) From science to policy through transdisciplinary research. Environ Sci Policy $11: 46-53$

Poteete AR, Janssen MA, Ostrom E (2010) Working Together: collective action, the commons, and multiple methods in practice. Princeton University Press, Princeton, New Jersey

Punt AE, SmithAM (1999) Harvest strategy evaluation for the eastern stock of gemfish (Rexea solandri). ICES J Mar Sci 56: 860-875

Reyers B, Roux DJ, Cowling RM, Ginsburg AE, Nel JL, O'Farrell P (2010) Conservation Planning as a Transdisciplinary Process. Conserv Biol 24 (4): 957-965

Rice JC, Garcia SM (2011) Fisheries, food security, climate change, and biodiversity: characteristics of the sector and perspectives on emerging issues. ICES J Mar Sci 68 (6): 1343-1353

Smith ADM, Sainsbury KJ, Stevens RA (1999) Implementing effective fisheries-management systems - management strategy evaluation and the Australian partnership approach. ICES J Mar Sci 56:967-979

Urwin K, Jordan A (2008) Does public policy support or undermine climate change adaptation? Exploring policy interplay across different scales of governance. Global Environ Change 18 (1) 
White CJ, Grose MR, Corney SP, Bennett JC, Holz GK, Sanabria LA, McInnes KL, Cechet RP, Gaynor SM, Bindoff NL (2010) Climate Futures for Tasmania: extreme events technical report. Antarctic Climate and Ecosystems Cooperative Research Centre, Hobart, Tasmania Wilson DC, Nielsen JR, Degnbol P (eds) (2003) The fisheries co-management experience: Accomplishments, challenges and prospects. Kluwer Academic, Dordrecht, The Netherlands 


\section{School of Economics and Finance Discussion Papers}

2013-20 Towards a Diagnostic Approach to Climate Adaptation for Fisheries, P. Leith, E. Ogier, G. Pecl, E. Hoshino, J. Davidson, M. Haward

2013-19 Equity Portfolio Diversification with High Frequency Data, Vitali Alexeev and Mardi Dungey

2013-18 Measuring the Performance of Hedge Funds Using Two-Stage Peer Group Benchmarks, Marco Wilkens, Juan Yao, Nagaratnam Jeyasreedharan and Patrick Oehler

2013-17 What Australian Investors Need to Know to Diversify their Portfolios, Vitali Alexeev and Francis Tapon

2013-16 Equity Portfolio Diversification: How Many Stocks are Enough? Evidence from Five Developed Markets, Vitali Alexeev and Francis Tapon

2013-15 Equity market Contagion during the Global Financial Crisis: Evidence from the World’s Eight Largest Economies, Mardi Dungey and Dinesh Gajurel

2013-14 A Survey of Research into Broker Identity and Limit Order Book, Thu Phuong Pham and P Joakim Westerholm

2013-13 Broker ID Transparency and Price Impact of Trades: Evidence from the Korean Exchange, Thu Phuong Pham

2013-12 An International Trend in Market Design: Endogenous Effects of Limit Order Book Transparency on Volatility, Spreads, depth and Volume, Thu Phuong Pham and P Joakim Westerholm

2013-11 On the Impact of the Global Financial Crisis on the Euro Area, Xiaoli He, Jan PAM Jacobs, Gerald H Kuper and Jenny E Ligthart

2013-10 International Transmissions to Australia: The Roles of the US and Euro Area, Mardi Dungey, Denise Osborn and Mala Raghavan

2013-09 Are Per Capita $\mathrm{CO}_{2}$ Emissions Increasing Among OECD Countries? A Test of Trends and Breaks, Satoshi Yamazaki, Jing Tian and Firmin Doko Tchatoka

2013-08 Commodity Prices and BRIC and G3 Liquidity: A SFAVEC Approach, Ronald A Ratti and Joaquin L Vespignani

2013-07 Chinese Resource Demand and the Natural Resource Supplier Mardi Dungy, Renée Fry-McKibbin and Verity Linehan

2013-06 Not All International Monetary Shocks are Alike for the Japanese Economy, Joaquin L Vespignani and Ronald A Ratti

2013-05 On Bootstrap Validity for Specification Tests with Weak Instruments, Firmin Doko Tchatoka

2013-04 Chinese Monetary Expansion and the US Economy, Joaquin L Vespignani and Ronald A Ratti

2013-03 International Monetary Transmission to the Euro Area: Evidence from the US, Japan and China, Joaquin L Vespignani and Ronald A Ratti

2013-02 The impact of jumps and thin trading on realized hedge ratios? Mardi Dungey, Olan T. Henry, Lyudmyla Hvozdyk

2013-01 Why crude oil prices are high when global activity is weak?, Ronald A Rattia and Joaquin L Vespignani

Copies of the above mentioned papers and a list of previous years' papers are available from our home site at http://www.utas.edu.au/economics-finance/research/ 